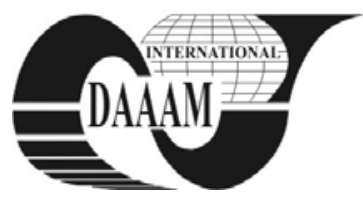

\title{
WOOD TEXTURE INFLUENCE ON TEMPERATURE FIELDS
}

\section{PIVARCIOVA, E[lena] \& CERNECKY, J[ozef]}

\begin{abstract}
The paper is aimed at visualization and analysis of temperature fields. The aim was to gather time dependencies of wood combustion, heat transfer development and the entire view of temperature fields in dependence on wood texture.

Key words: holography, holographic interferometry, temperature field, wood
\end{abstract}

\section{INTRODUCTION}

To visualise temperature fields in a transparent environment as well as to visualise various other parameters in mechanics of fluids and in other areas, there are used optical visualization methods (Cernecky, Koniar, 2010). The research of transparent inhomogeneities (thermal, concentration, or other fields in transparent fluids) is most frequently carried out by an interferometric method which enables us to visualise inhomogeneities in fluids thanks to their different refractive indices.

\section{FUNDAMENTAL TERMS}

Temperature field is defined as a distribution of temperatures in individual points of a body in a certain time moment. In general the field is three-dimensional and it changes with a position and time. Such a field is called nonstable, non-stationary. Stationary field is a field not changing with time (stable), to simplify calculations usually considered as one-dimensional.

According to the fact whether the temperature $T$ is a function of one, two or three coordinates, there is one-, twoand three- dimensional field.

In the Fig. 1 there is a schematic illustration of the temperature development in fluids and in a plane wall during heat transfer.

Temperature field is a scalar parameter. Connection of points with the same temperature creates an isothermal line (in one-dimensional fields) or isothermal area (in multidimensional fields). The changes of temperature occur only in directions transecting isothermal areas while the biggest

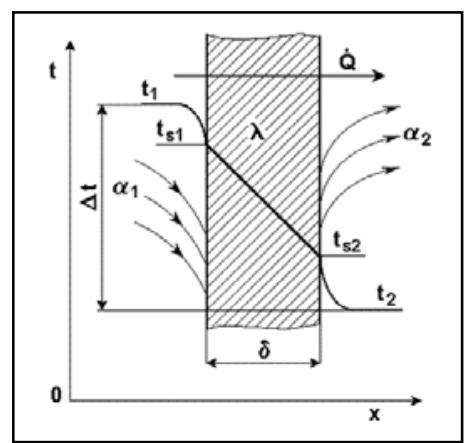

Fig. 1. Temperature development in fluids and in a plane wall during heat transfer (Ferstl, 2003); $t$ - temperatures, $\alpha-$ coefficient of heat transfer, $\delta$ - wall thickness, $Q-$ thermal flow

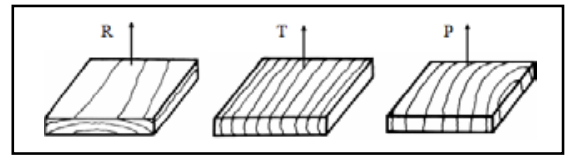

Fig. 2. Wood test specimens with various wood texture ( $\mathrm{R}$ - radial, $\mathrm{T}$ - tangential, $\mathrm{P}$ - longitudinal direction)

change occurs in the direction of the normal line no towards the isothermal area.

The limit of the ratio of temperature increment to the distance of isothermal areas in the direction of the normal line is called temperature gradient (Michejev, 1952):

$$
\lim _{\Delta n o \rightarrow 0} \frac{\Delta T}{\Delta n o}=\frac{\partial T}{\partial n o}=\operatorname{grad} T
$$

where grad $T$ - temperature gradient, $\Delta T-\quad$ temperature increment, $\Delta n o$ - direction of isothermal lines in the direction of the normal line.

Texture of wood is a wood grain visible on the section of wood and it is created by its structure e.g. annual rings, pith rays, arrangement of wood fibres and so on. For investigation of the temperature fields the test specimens of four wood species (beech, oak, spruce, poplar) with dimensions of $43 \times 40 \times 10 \mathrm{~mm}$ in three various anatomical directions (longitudinal, radial, tangential) were used. In Fig. 2 the direction of heat transition is illustrated by an arrow.

\section{THE EXPERIMENT}

The aim of the experiment was to design and verify the method of temperature field visualisation over test specimens and to observe the heat transition through individual anatomic directions of wood for various wood species.

For observation of temperature fields the real-time holographic interferometry method (Koniar, 2008) was used as it offers (through recording of the refractive index field of the investigated environment) an integrated image about the size and shape of the temperature field in the particular time, with the possibility of further analysis and interpretation of the investigated phenomenon. A holographic variant of MachZehnder interferometer was used to visualise and measure temperature fields.

Interferometric visualisation of the temperature fields was mainly aimed at the thermal marginal layers close above the test specimen surface, at qualitative and quantitative analysis of temperature fields after certain times of heating of a test specimen by a point source (flame) from the below.

In the experiment we observed the area above the top side of the test specimen because it shows the best all three forms of heat transfer (conduction, radiation, convection).

Interference images were gradually recorded by a CCD camera. For better possibility of usage of analytical methods the holographic variant of Mach-Zehnder interferometer was set at 
infinite width of interference fringes, i.e. before the experiment the only one interference fringe was possible to be seen in the test space and after heating new interference fringes gradually appeared. The higher the temperature was, the more fringes appeared. A parameter which is possible to be measured in interferometry in this case is the number of formed interference fringes which correspond to the isothermal curves while an interference order is given to them.

\section{FINDINGS}

During the heat loading of the test specimens the heat transmits and consequently the wood mass gradually degrades. Close above the test specimen surface a thermal marginal layer is created where it is possible to investigate the interference fringes.

In (Fig. 3 a-d) holographic interferograms of the temperature field above the heated test specimens recorded at the surrounding temperature of $17^{\circ} \mathrm{C}(290 \mathrm{~K})$ and the pressure of $98000 \mathrm{~Pa}$ are displayed. The balanced increase of the thermal marginal layer thickness is visible in the figures. The last of the displayed holograms (Fig. $3 \mathrm{~d}$ ) was recorded at the moment of glowing of the test specimen.

To assess holograms in a quantitative way it is necessary to determine distribution of the refractive index $\mathrm{n}(\mathrm{x}, \mathrm{y})$ and to calculate temperatures from the refractive index according to (Pavelek et al., 1977):

$$
T(x, y)=\frac{T_{\infty}}{1-0,805 \cdot \frac{T_{\infty}}{l \cdot p_{\infty}} \cdot\left(s-\frac{1}{2}\right)}
$$

where $T(x, y)$ - temperature distribution, $T_{\infty}-$ atmospheric temperature in the reference area, $p_{\infty}$ - pressure in the given space, $s$ - interference order, $\lambda$ - light wavelength, $l$ - model length.

We found that under thermal a gradual degradation of wood mass appears. The development of thermal destruction of individual wood species differs and the temperatures for individual wood species are relatively comparable.

The temperature grows exponentially in dependence on height from the specimen surface. In the tangential direction more intensive temperature growth can be observed.

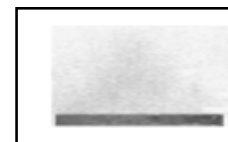

a)

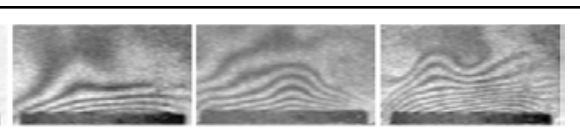

b) c) d)
Fig. 3. Holographic interferogram of the temperature field of the horizontal wood specimen (oak - parallel direction) recorded at the interferometer set to the infinite fringe width a) before the experiment (without heating)

b) during the experiment (beginning of heating - after 3 minutes of heating)

c) during the experiment (heating - after 7 minutes of heating)

d) at the end of the experiment (after 15 minutes of heating)

Temperatures of the individual wood species after 15 minutes of heating:

- Longitudinal direction: Beech, spruce, poplar burnt through $>$ Oak

- Radial direction: Spruce $>$ Beech $>$ Oak $>$ Poplar

- $\quad$ Tangential direction: Beech $>$ Spruce $>$ Oak $>$ Poplar

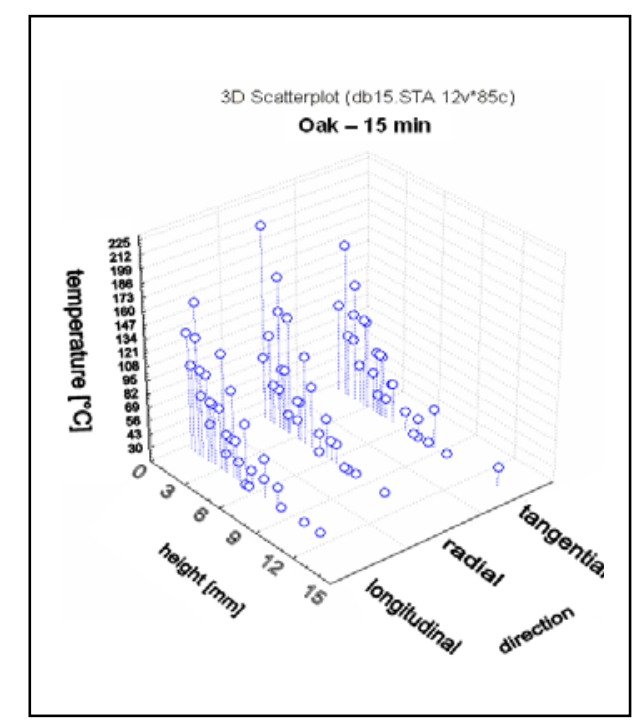

Fig. 4. Temperature dependence on direction and height

Anomalies occur which is caused by the fact the wood is anisotropic material (physical properties in different directions are different) and also by the influence of the surrounding environment (air flow in the laboratory, different air density in the place of measuring and in the surrounding environment).

The experiment limitations: the size of temperature field investigation is limited by the size of the viewing field of the object lens; temperature field investigation by the method of holographic interferometry is possible only in laboratory conditions.

\section{CONCLUSION}

Great importance is laid to efficiency of fire protection of wood. This topic also covers the visualization of temperature fields in a marginal layer on the interface wood - the surrounding environment. Via holographic interferometry the temperature fields above the test specimens were visualised. Using these fields we observed heat transition through the individual anatomic wood directions for various wood species.

\section{ACKNOWLEDGEMENTS}

The paper was written within the work on the VEGA 1/0498/10 project: Application of holographic interferometry in research of marginal layer in heat transition appliances.

\section{REFERENCES}

Cernecky, J.; Koniar, J. (2010) Research of local values of heat transfer coefficients in the area of heated curved wall. In: DAAAM 2010, Vienna, p. 315-316, ISSN 1726-9679

Ferstl, K.: (2003). Transfer of heat. Bratislava [May, 2011]. Available from: http://prenostepla.wz.cz (in Slovak)

Koniar, J. (2008). Research of velocity and temperature fields around a heated curved wall: dissertation thesis. Zvolen, 2008, 90 pg. (in Slovak)

Michejev, M. A. (1952). Basics of heat sharing. Praha Prumyslove vydavatelstvi (Industrial Publishing), 1952, 383 pgs. (in Czech)

Pavelek, M.; Ramik, Z.; Liska, M. (1977). Usage of holographic interferometry to visualise thermal marginal layers at natural convection in the air. Journal of Engineering, 28, 1977, č. 3, pg. 301-311. (in Czech) 